\title{
Socio-Organo Complexity, Project Schedule PERFORMANCE AND UNDERDAMPED TRANSIENT MOTION
}

\author{
Dimitris N. Antoniadis \\ Director of Programme, Project and PMO, DANTON PROGM, London, UK \\ Senior Lecturer, London Metropolitan College, London, UK
}

\begin{abstract}
Complexity is an inherent property of all systems and a result of interconnections. In projects various systems come together to deliver the required outcome(s). The most common type of project complexity mentioned / considered in practice is the technical complexity and this has always been considered a main factor which affects project performance. Despite that, projects are delivered by people who interface continuously and therefore are effected by complexity, and in particular that caused by socio-organo interfaces and the boundaries between the various teams and parties. This has not been investigated. Socio-organo complexity leads to reduction in performance if interconnections are not managed. Research has been carried out to understand the effects of complexity through project management processes on project schedule and performance, aiming towards the development of a tool and identification of actions that will enable the management of these effects. The author presents results of five case studies, which demonstrate that socio-organo complexity affects performance and these results have similarities with the behaviour of underdamped control systems. The results have significant implications on the way socioorganisational complexity can be managed, how processes are implemented, but also enable parallels to be drawn between the fields of project management and control systems. Considering control systems theory proposals are made in this paper for actions to be taken which will contribute towards the management of the effects of socio-organo complexity on projects.
\end{abstract}

\section{KEYWORDS}

Complexity, Interconnections, Project Schedule Performance, Control Systems, Crisis Management

\section{INTRODUCTION}

In the majority projects involve a large number of parties and therefore interconnections. Interconnections generate complexity [1], [2], [3] which has defined characteristics [4]. In the last few years a number of suggestions have been made regarding the management of its effects [2], [5],[6],[7], [8]. In practical terms the relationship between complexity and project performance has been considered as an exponentially decaying function. Various recommendations have been made for managing the technical and time element of complexity [2] but very little in terms of the soft side / socio-organisational aspects of complexity of interconnections and its effects [9]. However, processes such as selecting team members, structuring the project team, or the management style adopted (soft processes) and how these affect and are affected by complexity have not been considered. The author presents results from five case studies, conducted in the UK construction industry with client and construction organisations, and which investigated the effect of socio-organo complexity on project performance, as well as wider issues. The results demonstrate that the relationship is not that of an exponential decay curve but one of an underdamped transient motion. They also verify that there is a strong relationship between 
complexity and project performance and confirm the non-linearity of project management. The study outputs enabled the design, development and validation of a framework for the management of effects of complexity. Additionally, enable parallels to be drawn from the theory of systems control and which will allow for the implementation of actions that will enable the management of the effects of complexity on projects.

\section{BACKGROUND}

It has been shown that the management of projects occurs in a complex environment [10], [11], [12]. From earlier studies it has been shown that interfaces in projects have to be managed [1] and that these generate complexity [13], [2], [5]. From the complexity theory side it has been shown [3] that it is associated with the interconnection structures that connect / relate various objects and not the objects themselves and it is defined as the natural outcome of the interactions of dynamic relationships [9]. Applying complexity theory to the management of projects will enable the systematic consideration of the conditions that give rise to such complexity and project management can be defined as:

'The management of transient, dynamic and complex adaptive systems / agents, so as to deliver the expected change within certain parameters that are established by phenomenically ordered and stable environments' [9].

Previous studies [14], [15] highlight that in order to design more efficient project deliver systems and subsystems, from the soft view point, we need to understand and optimise the structuring of the interconnections of these systems and subsystems as well as the characteristics of the interconnections. This will enable project managers to prepare the set-up of the project and be ready to respond with the necessary actions at the appropriate stage.

From the review of three systems theories [4] has proposed that complexity has 18 distinct characteristics. 16 of these characteristics were identified as directly relevant, they were mapped onto project conditions and detailed description and relevance has been presented in [16].

Generally, in projects the environment is not only evanescent, but it is also characterised by complexity and reflects a dynamic process involving non-linear procedures [12]. Work that was done earlier on complexity in projects investigated mainly on the technical perspective [2], [6]but has not directly addressed the complexity effects on project schedule performance. Also, only recently the subject of complexity has been linked to non-technical project aspects such as communication, behavioural and social issues [7], [8]. Even so, these investigations have not been linked to the effects of socio-organo complexity of interconnections on project schedule performance.

The effect of complexity on project performance has not been explored. However, it is frequently assumed, in practical terms, that performance decreases as complexity increases. The relationship is considered to be one of an exponential decay (e.g. e-x) similar to an overdamped or critically damped system as those in Figure 1 below. 


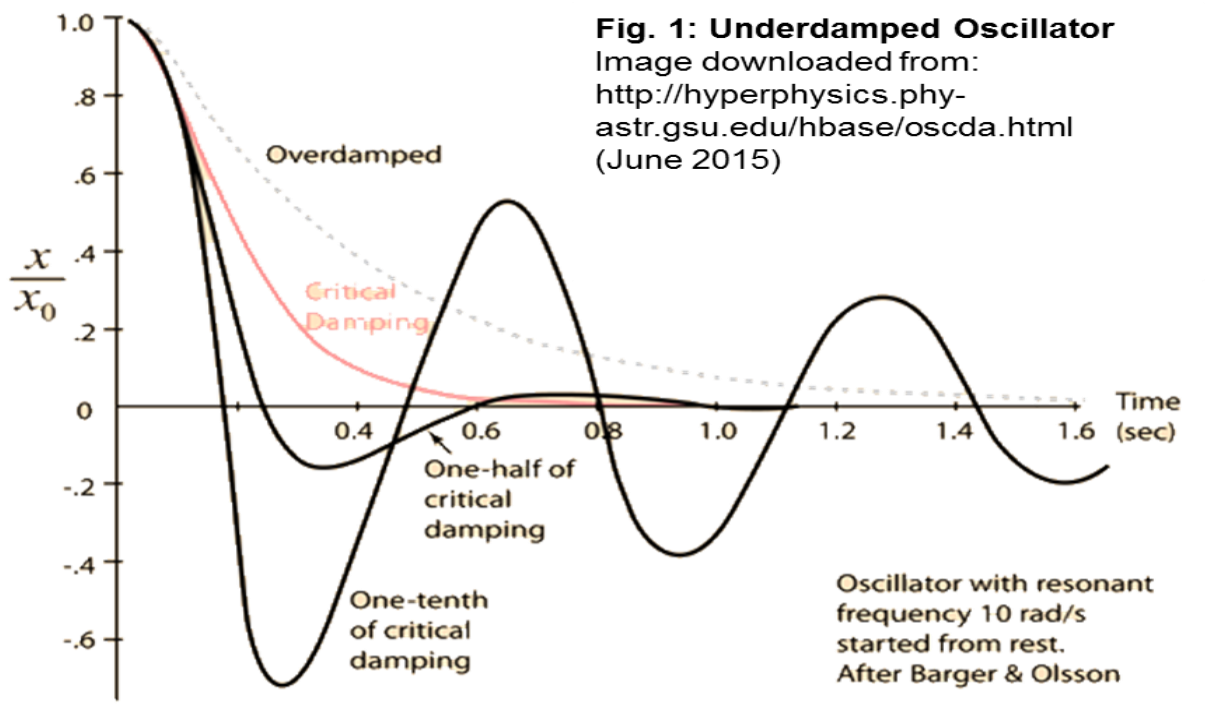

Figure 1.Underdamped Oscillator. Theoretical harmonic oscillations of systems under the effect of various damping devices.

In control systems the concept of motion, shown in Figure 1is a combination of two motions [17] expressed by the general mathematical function:

$$
x=\left[A e^{(-\zeta \omega t)}\right]\left[\sin \left(\omega\left(\sqrt{ }\left(1-\zeta^{2} t\right)\right)+a\right)\right]
$$

where:

- $\omega=$ undamped natural frequency

- $\zeta=$ damping ratio

The first part of equation $1,\left[\mathrm{Ae}^{(-\zeta \omega t)}\right]$, expresses the exponential decay element and the second part, $\left[\sin \left(\omega\left(\sqrt{ }\left(1-\zeta^{2} t\right)\right)+a\right)\right]$, expresses the circular frequency element [17].

In [18] the relationship between control systems and the effect of socio-organo complexity and project performance was established. The authors established the correlation and looked at a possible explanation / use of the equation of motion to describe project performance outcome.

In this paper the author describes the findings of the initial investigation and expands on the proposals / concepts made regarding the use of the equation of transient motion to manage the effects of complexity on project performance.

\section{The INVESTIGATION}

The subject of the effects of socio-organo complexity of interconnections on project performance was part of a wider research into complexity with particular interest in the processes of selecting team members, structuring project teams, the management style adopted, and project schedule performance. The relevant study question formulated for this particular objective was 'to investigate the inverse correlation between socio-organo complexity and project performance'. 
Having previously conducted interviews with project practitioners, in order to establish applicability of [4] complexity characteristics in project management, the study question was investigated by conducting closed design [19] multiple case studies.

In the timescales and commitment by respective organisations allowed, five projects were selected as case studies for nine weeks, or two project reporting periods, using an adaptive and flexible feedback mechanism. The number of case studies was considered appropriate because, as [19] states, 'if two or more cases are shown to support the same theory replication may be claimed and results will be considered more potent.' The decision to conduct multiple case studies was also based on the need to:

- Cover the whole project life-cycle and therefore establish more reflective outcomes.

- Minimise fears of uniqueness and artificial conditions surrounding the case(s), and

- Enable literal replication logic [19].

Considering the above, and in particular covering the whole project life-cycle, it was decided that the most appropriate method to investigate the study question, but not interfere with the observations, would be to request project teams to use the project schedule and monitor / record reasons for delay of the activities to be performed in the nine week predefined time. Results from earlier interviews with practitioners were used to establish, as will be described below, means to monitor delays. The project teams would monitor progress weekly and using a pick list they would record reasons for delay. Activities in the working project schedules will be of one week's duration so that the length of delay could be reasonably recorded and reported. Pre-arranged performance / progress review meetings with the researcher would enable capturing of data, clarifying queries, checking recorded data / reasons for delay in the performance log and confirming correctness of process followed. The extensive pick list of 'reasons for delay' was developed from the interviews and focused mainly, but not exclusively, on the three areas under investigation. An extract from this list is presented in Table 1.

Coding and brief descriptions were used to link 'reasons for delay' to one or more of the 16 complexity characteristics for ease of use by the project teams. The teams were also given 'reasons for delay' due to issues/causes raised prior to the commencement of the case studies. However, when/if these were used the practitioners were asked to elaborate at the reviews. During the reviews particular interest was paid to these reasons for delay since 'unpredictability' (a complexity characteristics), or incumbent pathogens [20] cause increase in complexity. Additionally, in preparation for the reviews, various scenarios where complexity could have a compounding effect on performance were identified so that these can be reviewed with the teams. 
Table 1. Extract from list for 'Reasons of activity delay' given to case study project managers.

\begin{tabular}{|c|c|c|}
\hline Code & Complexity Characteristic & Reason \\
\hline D300 & Self-reproduction & R01 - Lack of appropriate level of induction \\
\hline D700 & Emergence & R03 - Team cohesion \\
\hline B300 & Undefined values - structure & R04 - Inter-team issue (please elaborate) \\
\hline D100 & Co-evolution - team & R06 - Lack of Flexibility within the team \\
\hline $\begin{array}{l}\text { C500, } \\
\text { C300 }\end{array}$ & Attractors / Non-equilibrium & $\begin{array}{l}\text { R08 - No expertise within the team - external input } \\
\text { requested }\end{array}$ \\
\hline C402 & Non-linear - structure & R09 - Structure of team required improvement \\
\hline $\mathrm{C} 420$ & Non-linear-management & R10 - Authoritative approach caused problem in team \\
\hline D400 & $\begin{array}{l}\text { Downward causation - team } \\
\text { selection }\end{array}$ & $\begin{array}{l}\text { R11 - Team selection could have been better in terms of } \\
\text { tackling the task }\end{array}$ \\
\hline D410 & $\begin{array}{l}\text { Downward causation - } \\
\text { structure }\end{array}$ & R12 - Definition of work structure needed clarification \\
\hline D420 & $\begin{array}{l}\text { Downward causation - } \\
\text { management }\end{array}$ & R13 - Line of command needed clarification \\
\hline B100 & Unpredictability & $\begin{array}{l}\text { R14 - Problem from initial phases of project re-surfaced } \\
\text { and caused delay }\end{array}$ \\
\hline D110 & Co-evolution - structure & R16 - Communication between team and others \\
\hline $\mathrm{C} 210$ & Instability - structure & $\begin{array}{l}\text { R17 - Clarity of communication / instruction cause } \\
\text { confusion to the team which took some time to react to the } \\
\text { misunderstanding }\end{array}$ \\
\hline $\begin{array}{l}\text { C101, } \\
\text { C310 }\end{array}$ & $\begin{array}{l}\text { Autonomous Agents - team } \\
\text { Non-equilibrium - structure }\end{array}$ & $\begin{array}{l}\text { R18 - Restriction in people availability did not allow for } \\
\text { appropriate level of expertise }\end{array}$ \\
\hline $\mathrm{C} 211$ & Instability, & R19 - Unexpected activity due to: \\
\hline D510 & Mutability, & R20 - Non-availability of material \\
\hline D511 & & R21 - Change in higher level programme \\
\hline D500 & & $\begin{array}{l}\text { R22 - Causing an upset in the team (who probably did it } \\
\text { again) }\end{array}$ \\
\hline D520 & & R23 - Caused by unreasonable insistence by others \\
\hline D800 & Phase changes & $\begin{array}{l}\text { R2 } 24 \text { - Caused by not 'listening' to team feedback / } \\
\text { expertise }\end{array}$ \\
\hline
\end{tabular}

A simple method of performance measurement was established, discussed and agreed with participants. This is as follows:

- Activity performance $=($ Planned Duration $* \%$ Performance reported $) ;$ and

- $\quad$ Total Performance $=(\Sigma$ of Duration Achieved $/ \Sigma$ of Duration Planned $)$ irrespective of the time elapsed for the activity to be completed.

Five major construction organisations (clients and contractors) accepted to participate, and Board Directors were briefed on the requirements. The organisations agreed to put forward projects at the three different phases of the project lifecycle - feasibility, construction and commissioning with Project Managers (PMs) that had 10 or more years of experience. The PMs with the project teams were briefed extensively on the purpose and the process to be followed and were asked to provide the weekly progress data required. They were also asked to provide other project relevant information (Project Management Plans, etc) and the weekly meetings were arranged.

The relationship between project schedule performance and complexity, and in particular for the 16 complexity characteristics will be established by analysing the relationships between 'weekly $\%$ drop in performance against reason of delay', 'frequency of occurrence of coded reasons for delay' as well as 'frequency of complexity characteristics causing delay'. 
International Journal of Chaos, Control, Modelling and Simulation (IJCCMS) Vol.9, No.4, December 2020

Results will be deemed acceptable if replication is established between two or more cases [19] and by conducting validation interviews with PM / practitioners from different organisations.

\section{Results}

Overall implementation was over a period of ten months (2007 - 2008) and as described above the five case studies covered the whole project life-cycle (see Figure 2 below).

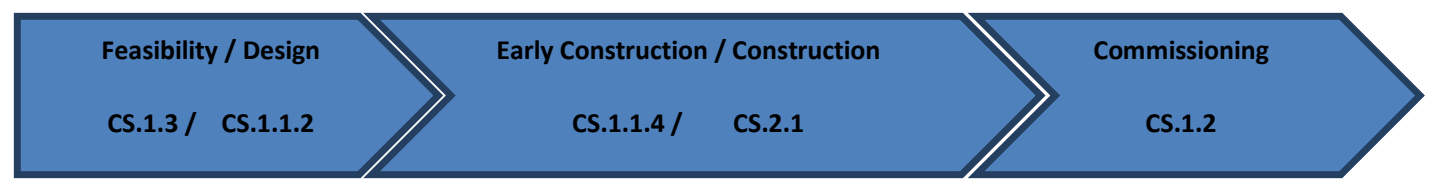

Figure 2. Project Life-cycle and respective case studies.

The case studies investigated and the type of organisation are shown below in Table 2 .

Table 2. Case study contributors by project stage

\begin{tabular}{|l|l|l|}
\hline Case Study & Project Stage & Description \\
\hline CS.1.3 & Feasibility & Waste Water Treatment works \\
\hline CS.1.1.2 & Design / Early Construction & Terminal Forecourt extension \\
\hline CS.1.1.4 & Construction & Redevelopment of Lounge \\
\hline CS.2.1 & Construction & Building - 28 luxury flats \\
\hline CS.1.2 & Commissioning & Chemical removal plant \\
\hline
\end{tabular}

Results from two of the five case studies - CS.1.1.2 and CS.2.1 - are shown below.

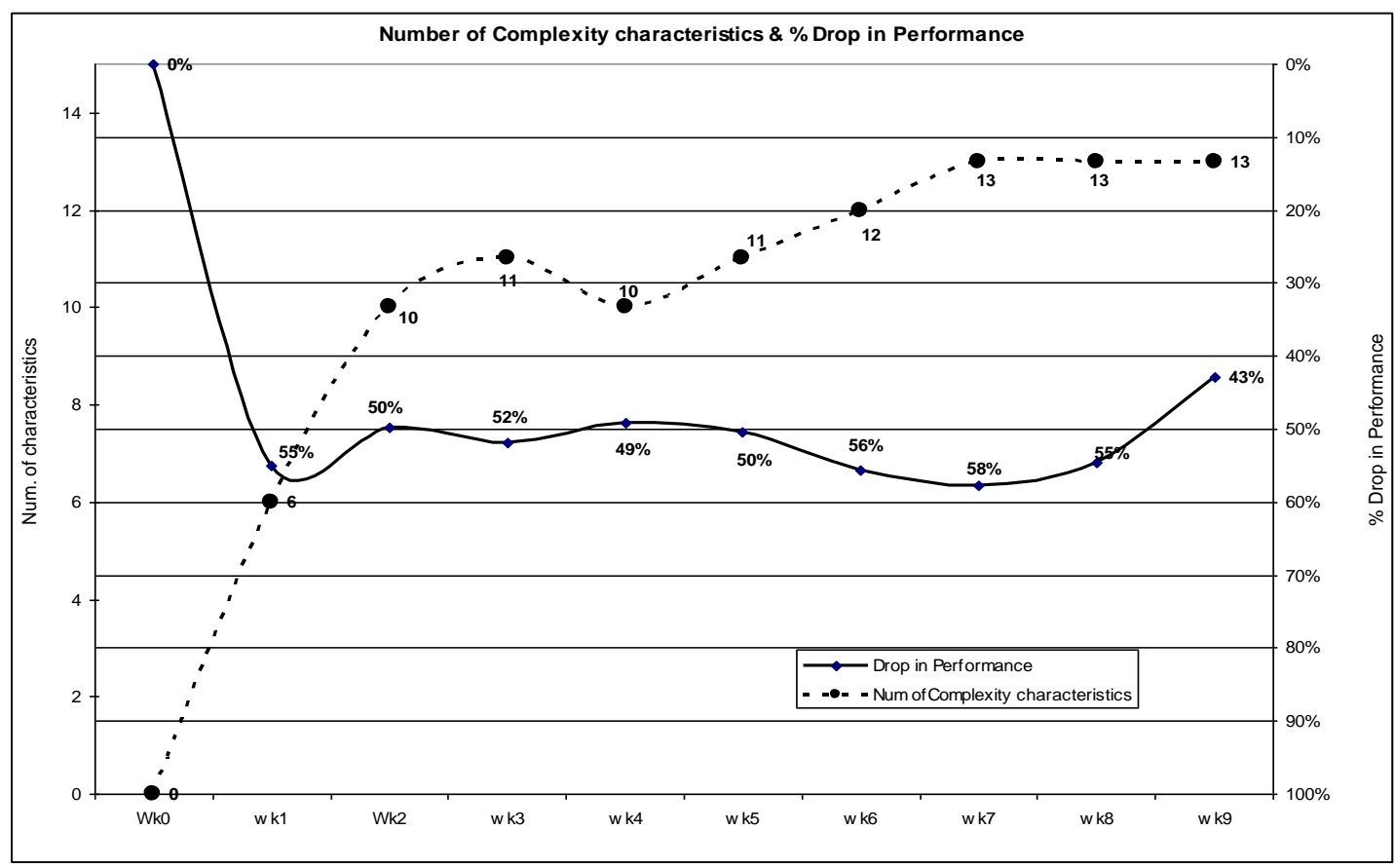

Figure 3. Case study CS.1.1.2 (Design/Early Construction). Indicates \% drop in performance versus number of complexity characteristics affecting performance during the nine weeks. 
International Journal of Chaos, Control, Modelling and Simulation (IJCCMS) Vol.9, No.4, December 2020

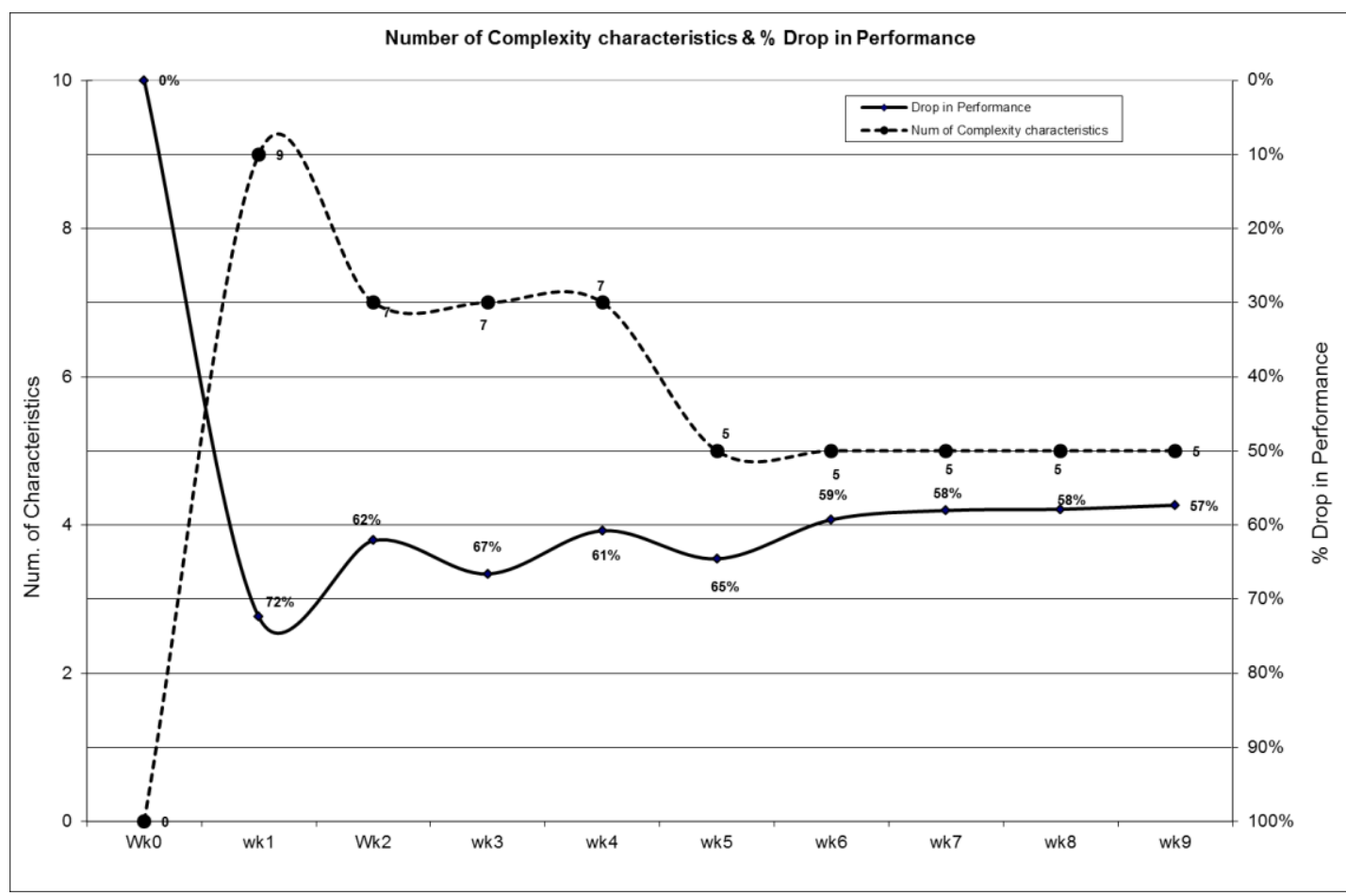

Figure 4. Case study CS.2.1 (Construction). Indicates \% drop in performance versus number of complexity characteristics affecting performance during the nine weeks.

Another way of indicating drop in performance was that of 'Cumulative planned durations' versus 'Cumulative achieved durations' which as can be seen in Figures 5 and 6 for case studies CS.1.1.2 and CS.2.1 only 57\% and 43\% of the planned activity durations was achieved (or 373 days of the 654 for CS.1.1.2 and 252 days of the 590 for CS.2.1) respectively.

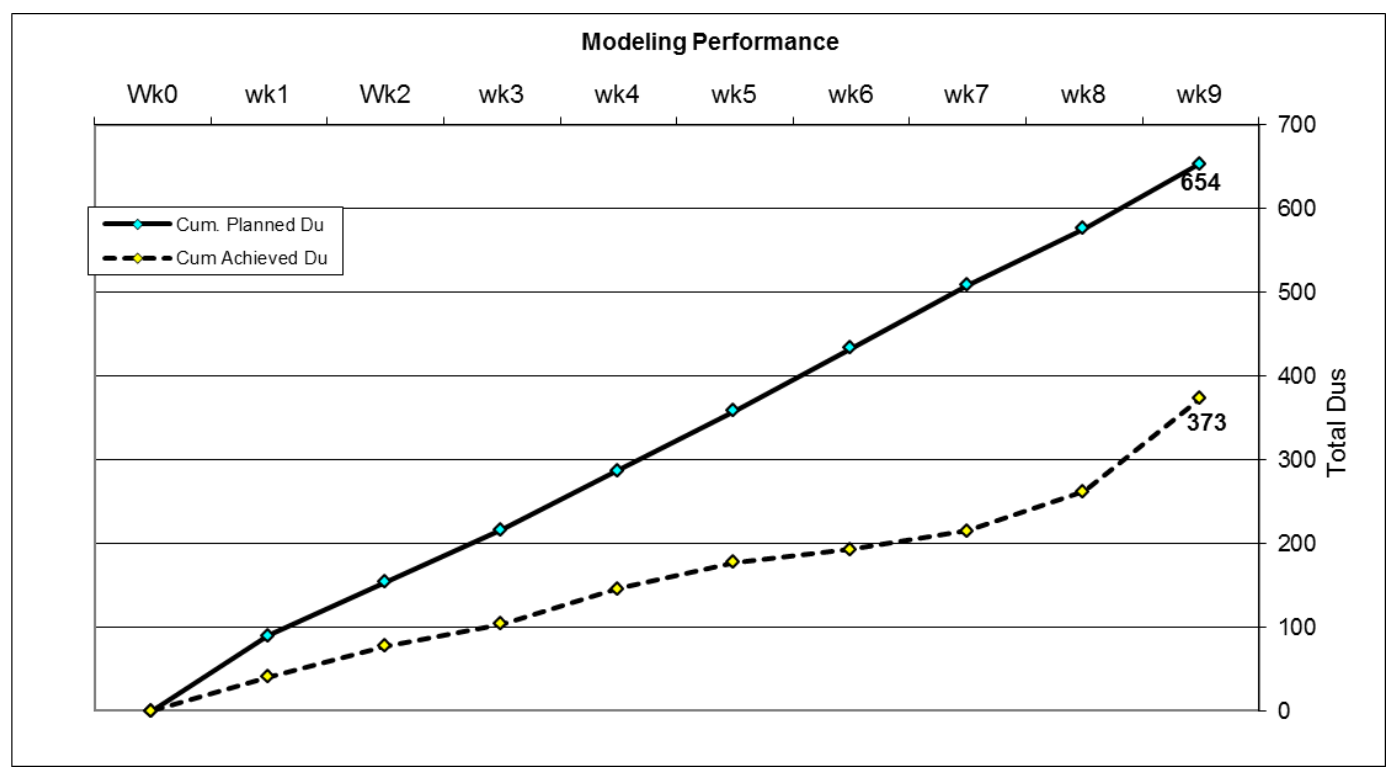

Figure 5. Case Study CS.1.1.2. Drop in performance measured against duration planned against duration achieved during the case study period. 
International Journal of Chaos, Control, Modelling and Simulation (IJCCMS) Vol.9, No.4, December 2020

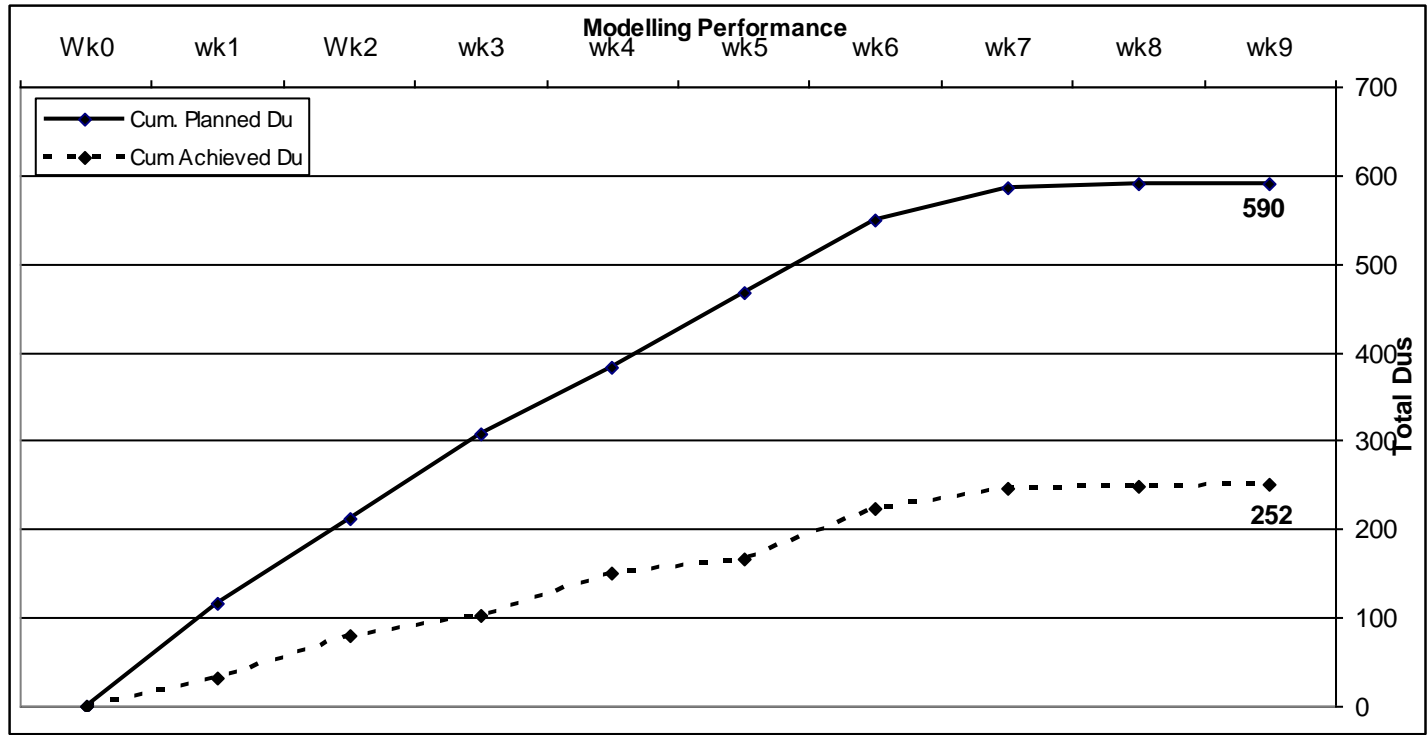

Figure 6. Case study G2.1. Drop in performance measured against duration planned against duration achieved during the case study period.

Results from all five case studies are shown below in Figure 7 and Figure 8 represents the average drop in performance for all the case studies.

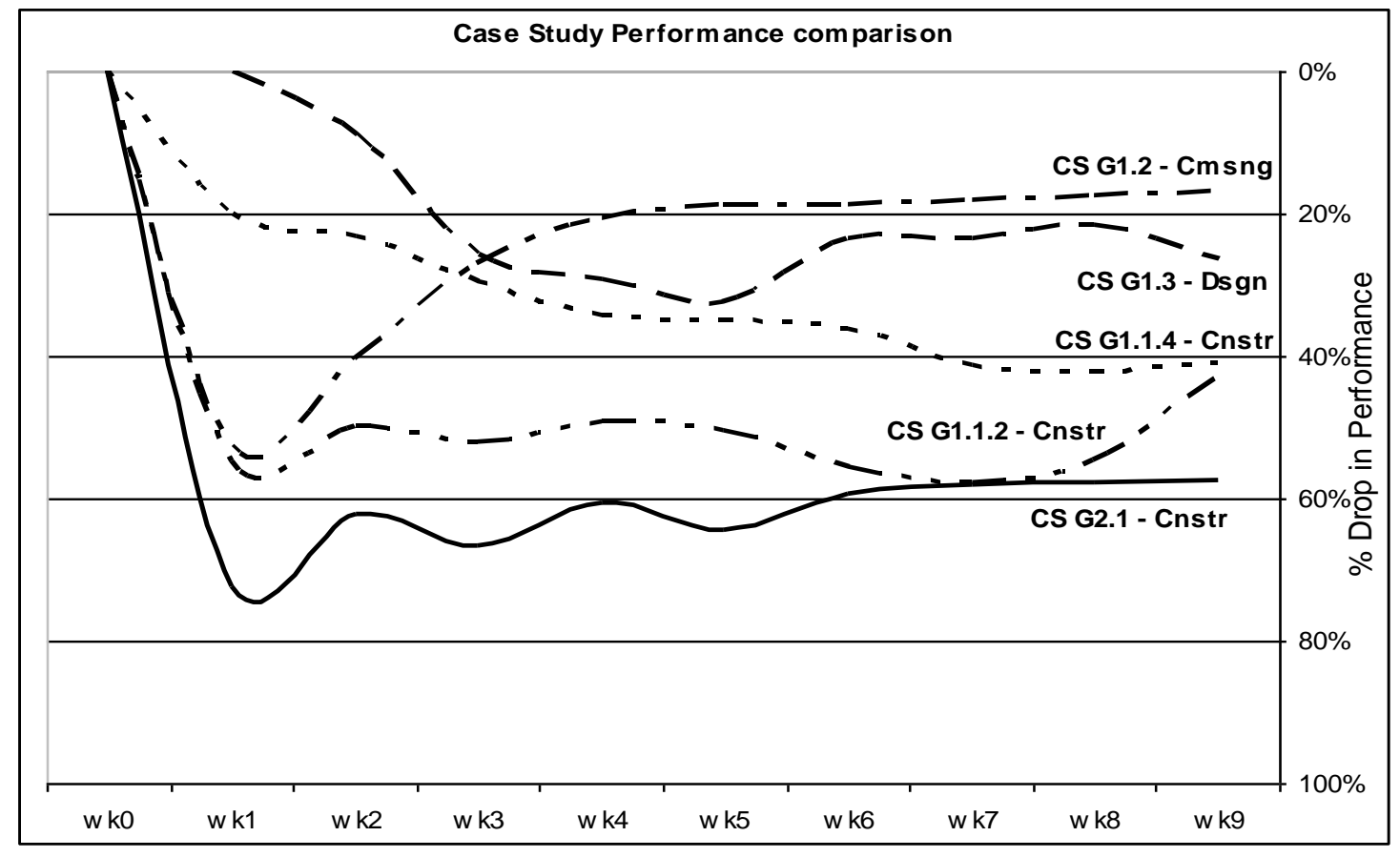

Figure 7.Summary of drop in performance due to the effects of complexity from all case studies. 


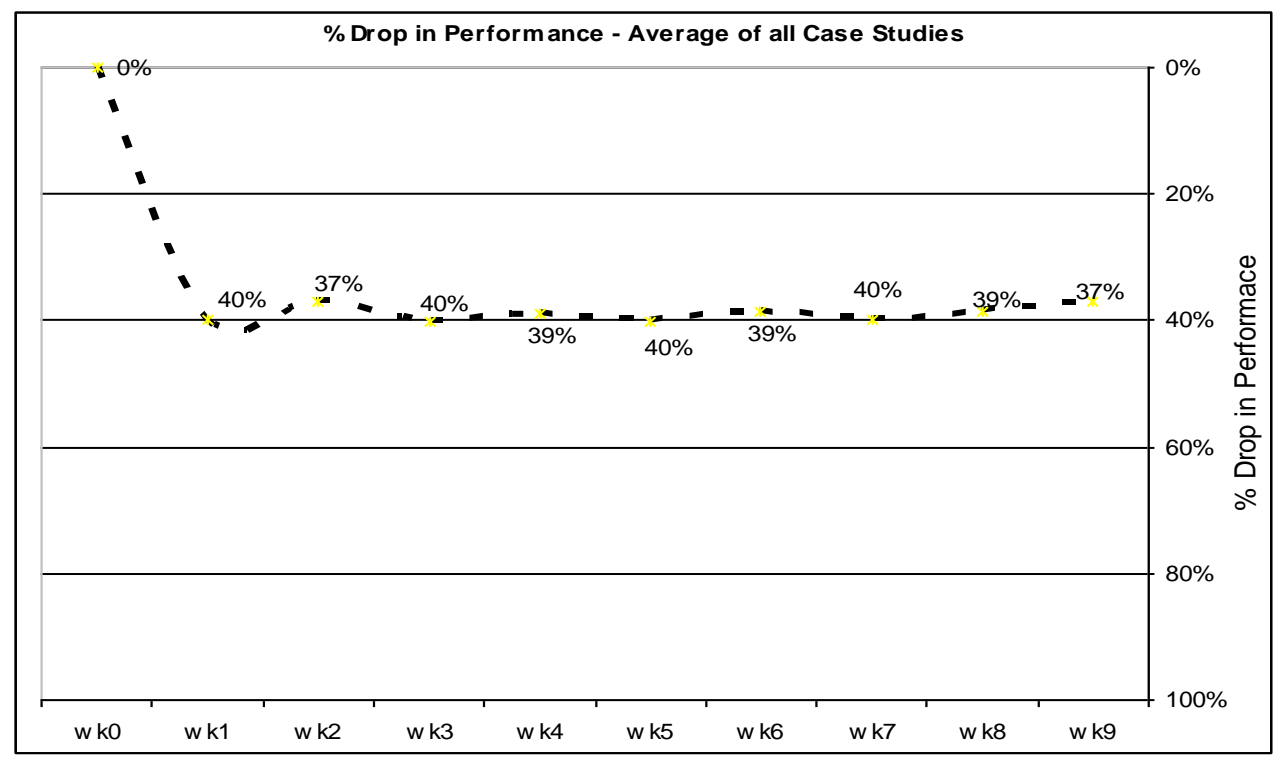

Figure 8. Average percentage performance dropdue to complexity for all case studies.

Validation of results was conducted through saturation interviews with project practitioners from different organisations, from the levels of Project Director to PM and the results were accepted as a true representation of the issues faced when delivering projects [9].

\section{Analysis}

Analysis of results is carried out holistically in order to establish inclusive and integrated deductions as well as replication [19]. The results shown in Figures 3 and 4 establish the inverse correlation between socio-organisational complexity of interconnections and project schedule performance and therefore prove the study question. Also, all the results, in particular that shown in Figure 8, indicate a clear correlation to the theoretical curve of underdamped transient motion (see Figure 1). Furthermore, the results from case studies CS.1.3 and CS.1.2 confirm relevant theory [21] regarding project team effectiveness at the initial as well as at the latter stages of the project life-cycle.

The results indicate that as the effects of the complexity impact work performance drops. Then as corrective actions are taken they introduce a positive effect (on the performance) but these do not bring back the performance to the required levels but at a plateau. From the progress reviews it was found that corrective actions included, bringing forward activities that can be performed at the time, pulling in additional resources, deferring activities, etc. For example, the PM of case study CS.2.1 had to delay groups of fit-out activities to a later stage. The case of the performance plateau and the reduction of the effects of complexity is also evidenced in case study CS.1.2 (Commissioning phase) where the project actually was delivered four weeks late.

All case study results, irrespective of the project phase, support the study question of inverse correlation between socio-organo complexity and project performance. Also, there is replication as well as consistency of the results. Additionally, there is clear resemblance with the longestablished theory of underdamped transient motion [17].

Further analysis on the findings and the relation between socio-organo complexity characteristics and project performance was conducted in the earlier paper [18] and these points will not be 
repeated in this paper. The discussion that follows will focus on the some of the results mentioned above but mainly bring up possible common points between control systems theory and the management of effects of complexity on project performance.

\section{DisCUSSION}

The results and analysis presented confirm replication. Furthermore, there is a clear indication that as the effect of complexity of interconnections increases, or not managed, project performance decreases. In particular the case studies for projects in construction indicate a circa $57 \%$ drop in project performance (see Figure 7) and an overall drop in performance of an average circa $39 \%$ for all project life-cycles (see Figure 8 ). This raises a number of questions regarding managing and delivering projects performance to the required level, how can this be improved, the level(s) of training and the tools available to the PMs and the teams, which will enable them to manage the effects of complexity and therefore project manage successfully and satisfactorily.

Also, questions are raised regarding project performance in the construction industry in the last 15 - 20 years since the publication of the Latham and Egan reports. It is obvious that, as we cannot say that complexity in projects is a new phenomenon and also the 'reasons for delay' are something new, we have not provided the appropriate tools to the PMs and their teams to improve project performance. As mentioned, [22] project management has remained static in a 60 's time warp influenced basically by control mechanisms. It is also questionable if further innovations based on the same principles (including those of conflict and risk management) will improve project performance.

The results proved that there is inverse correlation between socio-organo complexity of interconnections and project performance and that there is a direct relationship on the areas investigated. However, the characteristics of complexity of interconnections are and should be affecting the project management sub-processes, e.g. conflict management, monitoring and control, efficient use of resources, etc. [23]. Therefore, there should be a many-to-many relationship between complexity characteristics and project management sub-processes. The overall drop recorded should not change, but the management of the effects of socio-organo complexity could be enabled further through the other processes which then become contributory factors.

Let us reflect on the above findings and how actions taken when a crisis arises results from projects delivered under crisis management are always better than normal day-to-day projects.

As is always the case on a crisis the PM is asked urgently to pull together a team that will deliver the project within the required parameters. Therefore, from experience, but not limited, we almost always:

(please note: the corresponding complexity characteristics are shown in italics)

- Have a time limited project - management of Phase changes;

- Are given names of the stakeholders to whom they have direct / immediate access management of non-linearity;

- Have all red-tape removed - management of downward causation;

- Have anyone they want in the team that is an expert on the field(s) required, or the PM sets up their own team with no obstacles from anyone - introducing attractors;

- Have a small team working closely together - co-evolution and non-uniformity;

- Are allowed to self-organise - in addition to self-organisation we have self-modification, non-standard and mutability; 
- The team achieves the pick of maximum effort and effectiveness by achieving the required 'Emergence' levels - in addition to emergence we have also non-standardisation;

- Time response (that is ' $\Delta \mathrm{t}$ ') to anything urgent is so small that in many occasions it is barely noticed (further details on ' $\Delta \mathrm{t}$ ' will be discussed below).

Therefore, unknowingly, teams working on crisis projects are managing the effects of the complexity characteristics and achieve the required project performance. However, this does not mean that we have to treat everything as in a panic / crisis mode, because it will be unsustainable for any organisation.

The results prove the non-linearity of project management and the curve of drop in performance resembles that of an underdamped transient motion and therefore linking to the well-established theory of control systems.

Therefore, it should be possible to consider, transform and implement relevant 'solutions' from the control systems theory to project management.

With this in mind and in addition to points made in [18], some simple thoughts for further discussion are presented below.

In [18]a proposal was made to consider the formula of motion in underdamped systems and that this could be used to improve project performance by:

a) Minimise the circular frequency element $\left[\sin \left(\omega\left(\sqrt{ }\left(1-\zeta^{2} t\right)\right)+a\right)\right]$,

b) Identify the values of the damping ratio $(\zeta)$ and natural frequency $(\omega)$, which then will

c) Make the exponential decay function to equal $\mathrm{A}$ (see formula 1 above). Thus: $\mathrm{Ae}^{(-\zeta \omega t)}=\mathrm{A}$,

which therefore would mean that performance is near the $100 \%$. As depicted in Figure 9 below.

So, using the control systems theory there has to be a way to use relevant characteristics for ' $\zeta$ ' and ' $\omega$ ' in project teams so that the: $\lim (-\zeta \omega \mathrm{t}) \rightarrow 0$

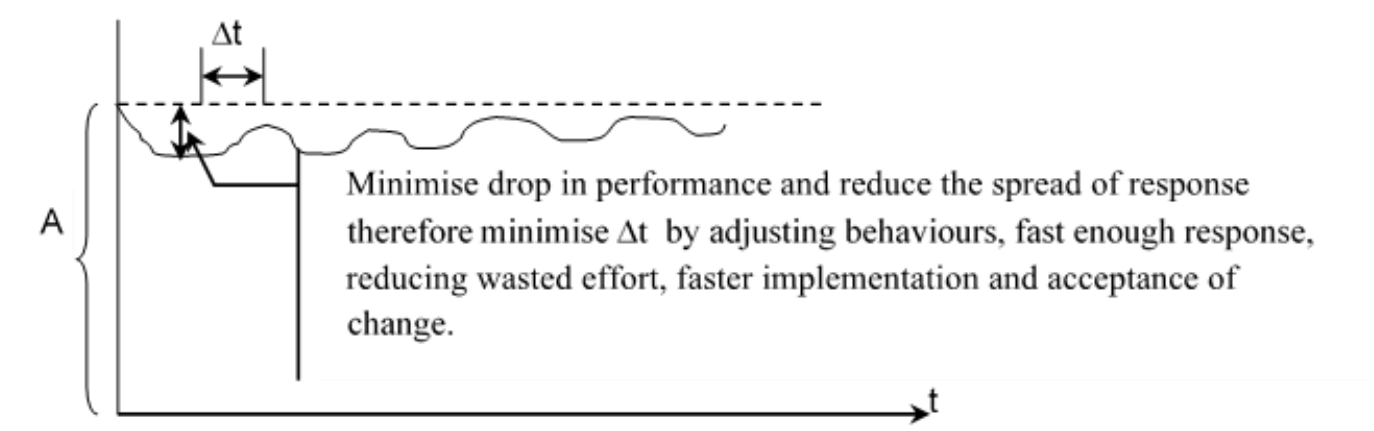

Figure 9. Graphical depiction of underdamped control systems curve applied to project performance.

Therefore, considering the above points and the formula of motion, shown again below, we could make the following inferences:

$$
x=\left[A e^{(-\zeta \omega t)}\right]\left[\sin \left(\omega\left(\sqrt{ }\left(1-\zeta^{2} t\right)\right)+a\right)\right]
$$


1) For a human system (team in the project environment) the ' $\omega=$ natural frequency' has to be relevant to the individuals' characteristics that come together to perform the required activities. The issue to be address here is that as in any 'high order' system the 'resonance' of the system has to be minimised in order to avoid catastrophic collapse.

Therefore, we could use Belbin's individual's characteristics to build the team.

For example, using Belbin's theory, if you put together A-type individuals you will never have a team environment as each individual is trying to lead the others. As we build the team using Belbin's characteristics, as well as carrying out Myers Briggs, then ' $\omega$ 'can be managed, therefore reducing resonance, and the team acts in self-organising way;

2) Regarding the ' $\zeta=$ damping ratio' for a human system (again in a project team environment), we can literally consider using the complexity characteristics as the elements that will dampen / manage the effects of complexity in the project through the respective processes.

So, we will need to propose which complexity characteristics can be included in ' $\zeta$ '. It should actually be that for each project management process the respective complexity characteristics are selected as part of the ' $\zeta$ ' that will enable minimising the circular frequency as well as the exponential decay elements of the formula of motion.

3) For ' $\Delta t$ ', the time element, this has to be the speed with which the team is informed and are able to react / respond to the events that will tend to overthrow the balance of the system through the interconnections formed between the systems. The faster the realisation and reduction of the ' $\Delta \mathrm{t}$ ' the quicker the reduction of both the circular and exponential elements of the formula of the motion.

However, ' $\Delta \mathrm{t}$ ' depends on the amount of information (received and/or transmitted) / events that occur, which unavoidably links to the amount of Entropy ' $S$ ' in the information (Shannon Entropy, [24]) received and transmitted. Shannon entropy is the expected value of the information in a message. The more uncertain, the higher the entropy of the transmitter.

As ' $\mathrm{t}$ ' or ' $\Delta \mathrm{t}$ ' depends on the amount of information / 'newness' introduced, this means that it will depend on the amount / level of surprise through information received and/or clarity of the information transmitted and with which the team will have to deal with. Therefore, by understanding and providing the means to manage the information uncertainty the PM / Team should be able to manage and reduce the reaction time ' $\mathrm{t}$ '/' $\Delta \mathrm{t}$ '. However, because of the effect of 'Entropy $S$ ' on information flow ' $\Delta \mathrm{t}$ ' $\rightarrow 0$ cannot be true, but it can be managed to minimise response time ' $\Delta \mathrm{t}$ '.

\subsection{Further Thoughts in Addition to the Above Points.}

In a project, as well as any 'high level' system, an event occurs that will tend to affect performance and therefore push down the underdamped system curve (the performance part). Therefore, it tends to increase the amplitude ' $A$ ' of the circular and exponential curves. The intensity of the effect of the event will depend on:

- The number of complexity characteristics that feed into it (through the respective processes);

- The importance of these and their effect at the particular point in time;

- What each complexity characteristic is and its dependence on the other characteristics;

- The leading process(es) at that point in time. 
Therefore, using concepts from systems controls, complexity and team building methods we can provide project teams with an approach that will enable them to (a) manage the effects of complexity and (b) increase project performance in the evanescent project environment.

\section{Conclusions}

As part of a wider research on managing complexity in project teams and in order to identify the effects of socio-organo complexity on project performance five case studies were conducted in construction projects. The results, for the three sub-processes investigated, proved the inverse relationship between complexity of interconnections and project performance, the non-linearity of project management as well as the correlation between the project performance drop and the theory of underdamped control systems. Replication was established between all five case studies with some minor variations for the projects in early design and commissioning.

The results indicated a considerable overall average drop in performance as complexity of interconnections increased significantly. However, the interlinked properties of the characteristics and those of the reasons for delay did not allow for establishing singularity of results, or otherwise overcoming the difficulty of identifying singular characteristics as causes of the drop in performance. Furthermore, the detection of the significant drop in performance is attributed to the fact that the case studies sought and extracted details that are not reported frequently, or seen as small issues that will be overcome, otherwise known as 'the devil is in the detail'.

The results indicate that PMs and their teams currently have no means available to manage the effects of complexity. Therefore, a requirement is identified for developing a framework that will enable the management of the effects of complexity through its characteristics. Further work has been carried out by the author in deciphering and mapping the complexity characteristics to the project management processes as well as the development of such a framework, which, however, will not be discussed further in this paper.

As highlighted in the discussion, findings also established links between actions taken under crisis management and complexity characteristics, which, unknowingly, are used to deliver successfully projects. Therefore, it is even more profound, as crisis management is not a sustainable solution, that understanding the effects of complexity and the application of measures to address its characteristics by project practitioners will enable earlier resolution of issues and successful delivery of projects.

The level of training and implementation of appropriate actions, when selecting project team members, structuring the project team and when considering the management style to be adopted, is also questioned by the results obtained. Therefore, the industry will need to consider improving the timing of implementation of actions and techniques. Construction organisations, from all sides, will also need to consider how to improve adjusting of behaviours and speed of response, reduction of wasted effort and improving acceptance of change in order to minimise the effect of complexity of interconnections.

In addition, the establishment of correlation between the effects of complexity on project performance and that of the underdamped systems provides the basis for interlinking solution modes. By drawing parallels between the two theories and providing possible solutions practitioners can be armed from the very early stages of the project(s) to manage both the effects of complexity as well as ensure improved project performance without the need for been in a continuous crisis management mode. 
The findings provide areas for further research in the:

- Applicability of the proposed variables from the underdamped systems and their use for improving project performance. That is, maximising variable ' $\mathrm{A}$ ' whilst managing damping ratio ' $\zeta$ ', using complexity characteristics, and natural frequency ' $\omega$ ', through individual / team characteristics;

- Detailed investigation of complexity characteristics and their use for project management in crisis management mode.

\section{REFERENCES}

[1] Thompson, J.D. (1967) Organisation in action. McGraw Hill, New York.

[2] Gidado, K.I. (1996), "Project Complexity: The focal point of construction production planning", Construction Management and Economics, Vol 14(3), pp.213-225.

[3] Lucas, C. (2000a), "Setting the Scene - Science, Humanity and Interaction", www.calersco.org Downloaded in August 2005.

[4] Lucas, C. (2000b), "The Philosophy of Complexity", www.calersco.org. Downloaded in August 2005.

[5] Williams, T.M. (1999) The need for new paradigms for complex projects. International Journal of Project Management. Vol 17(5), pp.269-273.

[6] Lillieskold J. and Ekstedt, M. (2003), "Managing Complex IT-Projects - A need for a tool addressing technical and organisational complexity", The Royal Institute of Technology, Industrial Information and Control Systems, Stockholm, Sweden.

[7] Geraldi, J. (2008), "The balance between order and chaos in multi-project firms: A conceptual model", International Journal of Project Management Vol. 26(4), 348-356.

[8] Girmscheid G. and Brockmann, C. (2008), "Complexity of Megaprojects. The inherent complexity of large scale engineering projects”, Project Perspectives 2008, Vol. XXIX, 22 - 26.

[9] Antoniadis, D.N. (2009), Managing Complexity in Project Teams, PhD Thesis, Loughborough University, UK.

[10] Davidson Frame, J. (2002) The new Project Management. Tools for an age of rapid change, complexity and other business realities. Second edition, 2002 Jossey-Bass.

[11] Jaafari, A. (2003) Project Management in the age of complexity and change. Project Management Journal, Vol. 34(4), pp. $47-57$.

[12] Bertelsen, S. (2004), "Construction management in a complexity perspective", 1 st International SCRI Symposium, 30-31 March 2005, University of Salford, UK.

[13] Baccarini, D. (1996), “The Concept of Project Complexity - a Review”, International Journal of Management Reviews Vol 14(4), 201-204.

[14] Loosemore, M. (1998) Social Network Analysis: using a quantitative tool within an interpretative context to explore the management of construction crises; Engineering, Construction and Architectural Management. Vol 5(4). p.315-326.

[15] Mead, S.P. (2001) Using Social Network Analysis to Visualise Project Teams. Project Management Journal, December 2001, pp. 32-38.

[16] Antoniadis, D.N., Edum-Fotwe, F.T., Thorpe, A. (2006), "Project reporting and Complexity", In: Boyd D (ed) Proceedings of 22nd annual conference ARCOM, UCE Birmingham, September 2006.

[17] Beards, C.F. (1981) Vibration Analysis and Control System Dynamics. Ellis Horwood. Chichester.

[18] Antoniadis, D.N., Edum-Fotwe, F.T. and Thorpe, A. (2011), "Socio-organo complexity and project performance", International Journal of Project Management, Vol. 29(7), 808-816.

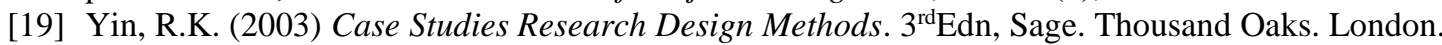

[20] Busby J.S. and Hughes, E.J. (2004), "Projects, pathogens and incubation periods", International Journal of Project Management, Vol. 22(5), 425-434.

[21] Moore, D.R. (2002), "Project Management: Designing Effective Organisational Structures in Construction", Malden MA: Blackwell Science.

[22] Morris, P.W.G. (1994), "The Management of Projects”, Thomas Telford. London.

[23] Collins, A. and Baccarini, D. (2004) Project Success - A Survey. Journal of Construction Research Vol 5(2), pp. 211- 231. 
International Journal of Chaos, Control, Modelling and Simulation (IJCCMS) Vol.9, No.4, December 2020

[24] Shannon, C.E. (1948) A mathematical theory of communication'. Bell System Technical Journal 27(3), pp. 379-423. Also in:https://en.wikipedia.org/wiki/A_Mathematical_Theory_of_Communication. Downloaded in March 2018.

\section{AUTHOR's SHORT BIOGRAPHY}

Dimitris has more than 30 years' experience in Programme and Project Management positions having covered project phases from concept to handover and operation / maintenance.

He held Senior Management posts in major utilities, infrastructure and construction organisations delivering programmes of works ranging from $£ 250 \mathrm{M}$ to $£ 3.2 \mathrm{Bn}$.

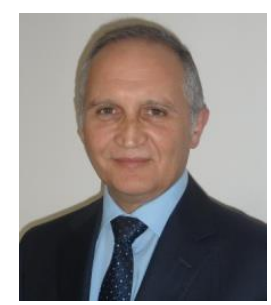

As Head of Programme Management Office (PMO) he has set up and run the departments within challenging partnering environments, setting up all the processes from governance to reporting.

He has also led / co-led major business transformation programmes for Client organisations in UK and abroad integrating project management software tools with ERP systems.

He is the author of the book 'Demystifying Project Control'; contributed chapters in books on complexity, leadership and other project management topics and has written a number of journal and conference papers. He has been a guest speaker at International conferences on various project management topics; he has lectured the complete project management module for undergraduates and also a guest lecturer to postgraduate courses at UK Universities.

He was awarded the $\mathrm{PhD}$, from Loughborough University, UK, for his research on the subject of 'Managing Complexity in Project Teams'.

He is a Fellow of the APM and the Chartered Management Institute (CMI).

Parts of his work can be seen in www.danton-progm.co.uk 